\title{
Conception of an SNS App for EFL learning in China Based on a Questionnaire Survey
}

\author{
Jun Ge \\ School of Educational Information Technology \\ Central China Normal University \\ Wuhan, China \\ School of Humanities and Social Sciences \\ National University of Defense Technology \\ Changsha, China \\ jinjiaba@126.com
}

\author{
Cai-Ping Xiong, Yue Zhang \\ School of Educational Information Technology \\ Central China Normal University \\ Wuhan, China \\ cpxiong@163.com, zhangyue998@mails.ccnu.edu.cn
}

\begin{abstract}
SNSs have been widely used in EFL (English as a Foreign Language) learning world-wide. In China, QQ, a very popular SNS, has also been widely used for EFL learning. However, there are some problems regarding the use of $Q Q$ in this field. This paper presents a study which tried to find out those problems through a questionnaire survey. Results showed that problems did exist from the perspectives of organization, manner, content and participant of discussion. Based on the identified problems, the study proposed a conception of an SNS app for EFL learning and illustrated how it worked and what its features were. As expected, this app is to help EFL learners practice more by facilitating meaningful communications in English, and thus improve their EFL skills.
\end{abstract}

Keywords-SNS; EFL; ICT; WTC

\section{INTRODUCTION}

EFL (English as a Foreign Language) has gained an increasingly important position in China since international communications at various levels and in various fields are getting deeper and more frequent between China and other countries. However, EFL learning is confronted with some bottleneck difficulties. For school-based EFL learning, the major disadvantage is the lack of language practice caused by the deficiency of curriculum time and practice outside class. Despite that learners receive instruction and practice in the language classroom, classroom and real-world interactions differ in that students transform from a language learner to a language user [1]. However, the reality is that the massproduced students are still "deaf and dumb" even after years of intensive exposure to the target language [2]. For post-school EFL learning, the problem is that it is hard for the social learners to find the right place and people to work with. In the new era, there is an essential need and the possibility to pool the social learners with the same EFL interest together via the latest development of information and communication technology (ICT).

Socialization and communication tools in social networks are both important and together they promote language learning [3][4]. During recent years, social network sites (SNSs)

This study was supported by the National Natural Science Foundation of China (project number: 71433004) and by the Science and Technology Department of Hunan Province of China (project number: 2014FJ3072)

Cai-Ping Xiong is the corresponding author of the paper. have shown great potentials in EFL learning, such as providing a platform for building online language learning communities and facilitating language practice. Ferdig (2007) states that social networking improves social interaction, facilitates active and social learning, and helps construct knowledge within a constructivist environment [5]. In China, QQ, a popular SNS run by the company Tencent Holdings Limited, has already been widely used for EFL learning. If we search for QQ groups with the keyword "English", we will find numerous groups, which proves that QQ has gained an important role in EFL learning. However, since QQ is not specifically designed for EFL learning, there will be some disadvantages. This study conducted a questionnaire survey in a popular and active EFLlearning QQ group to figure out what the disadvantages were perceived by those stakeholders, and aimed at proposing a conception of an SNS app for EFL learning which avoided those identified disadvantages.

\section{LITERATURE REVIEW}

In this section, relevant studies investigating willingness to communicate (WTC), computer-mediated communication (CMC) and SNSs will be reviewed to explore what the advantages are that SNSs have upon language learning.

\section{A. WTC and Language Learning}

Sociocultural theory holds that learning is social in nature and meaning is derived through language use within the social context [6]. It indicates that communication with peers is critically important, especially for language learning. Contemporary second language (L2) pedagogy emphasizes communicative interaction in class to develop learners' communicative competence. However, not all individual learners are willing to communication in another language. Willingness to communicate (WTC) is defined as the likelihood of participating in communication when one has the option to do so [7]. Studies have indicated that learners who have higher perceptions of their communicative competence and experience a lower level of communication anxiety tend to be more willing to initiate communication [8]. WTC has a close correlation with motivation and English proficiency, and 
it is beneficial to create authentic situations to enhance students' WTC outside class [9].

\section{B. CMC and Language Learning}

Generally, CMC refers to communication that is mediated by a computer interface [10]. CMC enables language learners with network access to interact with peers in either synchronous or asynchronous modes [11]. Studies have found that the use of CMC for language learning benefits EFL students and improved students' perceived confidence in using English [12]. Smith's (2004) study upon synchronous written $\mathrm{CMC}$ indicated that the lexical items covered in negotiation were more likely to be retained [13]. Sauro and Smith (2010) found that synchronous written CMC also significantly improved levels of syntactic complexity [14]. Yanguas (2010) found that video-type $\mathrm{CMC}$ interactions were very similar to face-to-face interactions and equally successful [15]. CMC might even offer potential benefits over face-to-face communication. For example, more inhibited and introverted learners may find $\mathrm{CMC}$ to be less threatening, and thus they will engage more [16]. Asynchronous CMC benefits students by permitting delayed response to questions to allow careful construction of grammar [17].

\section{SNSs and Language Learning}

SNSs are actually a form of CMC which relies much on the Internet. One of the most important functions of social networks is that they engage learners in authentic communication in meaningful contexts [18][19]. While relatively few in number, studies about using SNS in the language classroom have shown some positive effects on learning [20]. Hung and Yuen (2010) indicated that supplementing face-to-face courses with SNSs in university courses would promote feelings of social connection and lead to a positive attitude toward learning experience [21]. The power of SNSs in language learning has been identified in some studies involving Facebook and Twitter. Ellison, Steinfield and Lampe (2007) suggested that Facebook may lower barriers to communication as it offers different ways for users to connect, and encourage students with low satisfaction and low self-esteem to engage more in communication [22]. Facebook offers students opportunities to engage in meaningful language use with their peers [23]. The affordances of Twitter for language learning including building classroom community, connecting learners with communities beyond the classroom and supporting meaningful and engaged language learning in authentic contexts [24].

From the above mentioned, it can be concluded that SNSs have great potentials in language learning. However, the application of SNSs in China EFL learning has not been sufficiently investigated. This study aims at finding the problems of QQ as an SNS for EFL learning and proposing a new SNS app for China EFL learning based on the identified problems.

\section{METHODOLOGY}

\section{A. Design of the Questionnaire Survey}

In order to figure out the features and basic functions of the to-be-proposed SNS app, this study examined the learners' perceptions of QQ as a tool for EFL learning by administering a questionnaire survey. One of the QQ groups which was abundant in members and active in communication was chosen as the target of the survey. The questionnaire was in a Likert Scale format, containing 12 five-point questions which were to learn about respondents' perceptions of QQ-based EFL learning from four perspectives, namely organization, manner, content and participant of discussion. Five-point stands for strongly agree, and one-point stands for strongly disagree. These questions were designed based on the author's real experience in some QQ groups for EFL learning during the past eight months, i.e. they embodied the problems perceived by the author.

\section{B. Data Collection}

The survey was conducted in November of 2015 through the website www.wenjuan.com, which facilitated the production and distribution of the questionnaire. A link to the questionnaire webpage was created and posted in the target QQ group for EFL learning named Freedom of Speech. This group was chosen because it contained more than three hundred members and the number of active members was large (about one fourth of the total) and steady. Forty one valid respondences were collected and then analyzed in SPSS. The cronbach's alpha value is 0.74 , which indicates that reliability of the survey is fairly acceptable.

\section{Results}

The survey results are shown in TABLE I. Items 1-3 were to find out the problems regarding organization of discussion, items 4-6 for manner, items 7-9 for content and items 10-12 for participant. The results showed that all these statements were agreed to some extent by the respondents in that the scores were all close to 4 with the highest being 4.2 and the lowest being 3.71, which indicated that these identified problems did exist regarding the use of QQ for EFL learning.

TABLE I. Results OF THE Questionnaire SurVeY

\begin{tabular}{clcc}
\hline $\begin{array}{c}\text { Item } \\
\text { No. }\end{array}$ & \multicolumn{1}{c}{ Statement } & Mean & Std. Dev \\
\hline 1 & There is no organizer to host the discussions. & 3.88 & 0.78 \\
2 & Discussions in big groups are inefficient. & 4.20 & 0.64 \\
3 & It is difficult to find someone willing to talk. & 3.71 & 0.68 \\
4 & Test messaging is the major manner of & 4.07 & 0.79 \\
& communication. & 4.12 & 0.75 \\
5 & Realtime voice talks were rarely employed. & 3.95 & 0.80 \\
6 & Realtime video talks were rarely employed. & 4.00 & 0.74 \\
7 & Discussions are messy and scattered. & 3.85 & 0.85 \\
8 & Discussions are mainly about trivial things. & 4.15 & 0.73 \\
9 & Discussions cannot go deep into a certain theme. & 3.83 & 0.67 \\
10 & English levels of the group members vary a lot. \\
11 & It is difficult to find someone of the proximate & 3.76 & 0.80 \\
& English level as me. & & \\
12 & Talking to people whose English is much better & 4.05 & 0.80 \\
& or poorer than me will make me keep reticent. & & \\
\hline
\end{tabular}

a. The number of respondences $n=41$ 


\section{DISCUSSION}

\section{A. The Problems of $Q Q$-based EFL Learning}

From the survey results, the problems of QQ-based EFL learning were identified in four aspects, namely organization, manner, content and participant of discussion.

First, QQ-based EFL learning lacks proper organization. Although there is a sponsor for each QQ group, no one is supposed to be the organizer or host of the talks, which makes the discussions chaotic. For newcomers, they will feel at a loss in that no one will provide any help or directions for them. Moreover, because of the lack of organization, the discussions will usually occur in the big group, which makes the communication inefficient since the number of participants is much bigger than the desired one for online discussions. Each participant may have few chances to articulate their opinions and it will be difficult to make the discussion consistent throughout the communication. Furthermore, without proper organization, it is uneasy for the learners to find the right persons who are willing to talk to him/her.

Second, QQ-based EFL discussions lack alternatives regarding the manner of communication. According to the survey, the major manner of communication is text messaging. There are some advantages for this manner such as giving learners enough time to collect ideas and elaborate the typed texts. However, training of the four English skills, namely listening, speaking, reading and writing, needs a variety of manners of communication. Text messaging may help improve reading and writing skills, but has a very limited influence upon listening and speaking. Unfortunately, voice and video talks which entail much use of listening and speaking skills are not given enough attention, while they contribute a lot to the improvement of the two skills.

Third, the content of the QQ-based EFL discussions is on a superficial level. In the above text, it has been claimed that proper organization is absent in QQ-based EFL learning. The direct consequence is that discussions are messy and scattered. The participant either talking about trivial things or switch from one topic to another frequently. There are no pre-set themes for the discussions, which makes them aimless and not penetrate into the depth of a theme. As a result, some learners enter the EFL group with plenty of passion while quit with depression and helplessness. Therefore, the fact that discussions stay on a superficial level will have a negative influence upon learners' participation and the establishment of a close learning community.

Forth, English proficiency of the learners in the QQ group vary a lot. QQ does give each member a rank, but it is based on the frequency of posting messages instead of English proficiency. Learners, especially the newcomers, take great pains to find the persons of the proximate English level as them However, the results of the survey showed that learners may keep reticent if their learning companions are much better or poorer in English than themselves. Hence, without a mechanism to cluster the learners with similar English proficiency, they tend to retreat from the discussions, and without enough language production, possibility of improving their English is low.

\section{B. Conception of a New SNS app for EFL Learning}

In some sense, QQ is successful as an SNS tool for EFL learning while it is also a failure because its benefits for EFL learning is limited. QQ is not to be blamed in that it is not an SNS specifically designed for this purpose. This paper will propose a conception of a new SNS app which avoids the identified limitations of QQ as an EFL learning tool.

\section{1) Design Principles}

In order to avert the limitations of QQ for EFL learning, this SNS app follows the design principles listed below: (1) This app will have the function of automatic organization of discussions; (2) This app will restrict the number of participants for each discussion within four; (3) Multi-manner communications are enabled and encouraged; (4) Theme-based discussions are enabled and enforced; (5) English proficiency of each learner will be identified and visible to other learners; (6) Volunteer/intended tutoring is enabled and encouraged. Moreover, both PC-based and mobile-device-based versions are expected since ubiquitous learning is emphasized today.

\section{2) A Conceptual Sketch of the App Interface}

Fig. 1 shows that there will be chatting rooms intended for participants of different English levels. In each room, there will be tables for different themes of discussion which is visible to the would-be participants. Each table will have at most four participants, and the manner of communication is displayed clearly.

\begin{tabular}{|l|l|l|l|l|l|l|}
\hline CET 1 & CET 2 & CET 3 & CET 4 & CET 5 & CET 6 & Mixed \\
\hline
\end{tabular}

Fig. 1. A demonstration of a room for discussion.

Fig. 2 shows that a round-table discussion under the theme of education is in progress. It is in a video talk mode with text messaging available simultaneously.

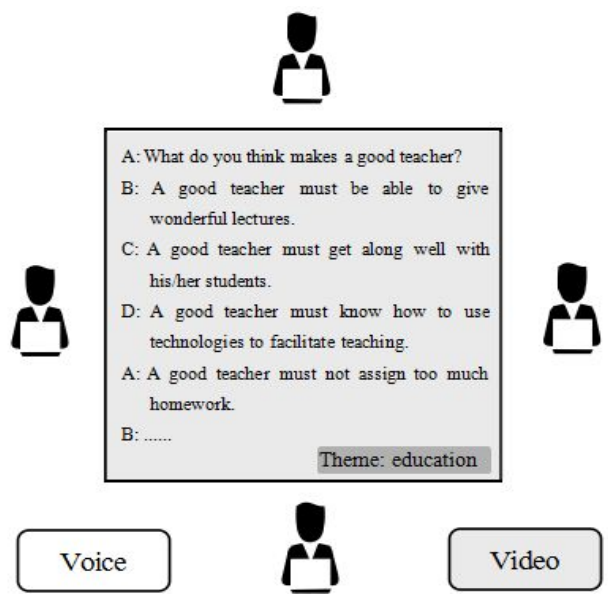

Fig. 2. A demonstration of a round-table discussion. 


\section{3) Procedure of Participating in a Discussion}

The procedure of participating in a discussion will be demonstrated through the experience of a virtual learner Sam. When registering online, Sam has to provide basic profiles of himself including his English proficiency level, which, the authors suggest, could be indicated by College English Test (CET) bands, ranging from band one to band six. Then from the interface, he may enter into the chatting room of the corresponding level, for example the room for CET 4 in Fig. 1. He may also choose the mixed room in which he can talk to others of different English levels. In the room, he will further select a table which presents a topic that he is interested in. This topic is set compulsorily by the learner who sits down first The table is open, i.e. a learner may sit down at any table as long as there is a seat available and it is not locked by the antecedent arrivers. After sitting down, he may participate in the discussion immediately. The default manner of communication is text messaging, but voice and video talks are also available upon the agreement of all the participants. Meanwhile, text messaging can co-exist with the other two manners. The manner of communication for each desk will be indicated clearly, which helps the newcomers better decide whether to join or not. The input texts will be displayed on the virtual desk in a form of scrolling. After a period of learning, if his English is improved, he may update his profiles and then can get the access to the room of the higher level.

\section{4) Features of the App}

This app is deliberately designed for EFL learning through meaningful online discussions. Therefore, its features lie in the support for sustained and in-depth discussions. First, this app organizes EFL discussions in an appropriate way. It presents different groups as separate tables for discussion, so the number of participants is restricted within four and each participant will have many chances to articulate. The difficulty of finding someone willing to talk is removed since anyone at the table sits down voluntarily to practice English. Second, the app provides and encourages different manners of communication. Learners can improve not only reading and writing skills through text messaging, but also listening and speaking skills through voice and video talks. Third, the app creates a well-round environment for theme-based discussions. Setting a theme for the discussion is a must for the first arriver at the table, which may make the discussion pertinent and profound. Forth, the app enables learners to find suitable learning companions who are of the proximate English level as them. Hence they are likely to speak more without feeling awkward. Fifth, the app provides a platform for tutoring since the participants around a table could be an instructor who is to give online tutoring. All in all, this app will help the registered learners practice more by facilitating meaningful communications via English, and thus improve their EFL skills.

\section{Limitations of the Study}

First, the questionnaire was designed based on the experience of the author in particular QQ groups for EFL learning, hence the perceived questions might not be comprehensive. Second, only one QQ group among the numerous was surveyed, which might reduce the representativeness of the data. Third, this study only presented a preliminary conception of the app including some mechanisms of operation, but no empirical study was conducted.

\section{CONCLUSION}

SNSs present as an important tool for EFL learning because of its strong support for meaningful language communications. In China, QQ is widely used for EFL learning, while there are some problems regarding the aspects of organization, manner, content and participant of discussion. This paper proposes the conception of a new SNS app for EFL learning which may well solve the identified problems of QQ-based EFL learning. With this app, learners will find the right learning companions much more easily, discussions will go deeper into the themes and different English skills will be covered through multi-manners of communication. Future studies could conduct larger scale surveys to identify the problems more accurately, and work out prototypes of the app to conduct empirical studies.

\section{ACKNOWLEDGMENT}

The authors would like to thank those who responded to the questionnaire survey.

\section{REFERENCES}

[1] S. Springer and L. Collins, "Interacting inside and outside of the language classroom," Language Teaching Research, vol. 12, pp. 39-60, 2008.

[2] H. Han, "Transforming EFL classes from lecturing to cooperative learning," Journal of Language Teaching and Research, vol. 5, pp. 948952, 2014.

[3] L. Lomicka and G. Lord (Eds.), The Next Generation: Social Networking and Online Collaboration in Foreign Language Learning. San Marcos, TX: CALICO, 2011.

[4] M. Sturm, T. Kennell, R. McBride and M. Kelly, "The pedagogical implications of web 2.0," in Handbook of Research on Web 2.0 and Second Language Learning, M. Thomas, Ed. Hershey, PA: Information Science Reference, 2009, pp. 367-384.

[5] R.E. Ferdig, "Editorial: examining social software in teacher education," Journal of Technology and Teacher Education, vol. 15, 5-10, 2007.

[6] S. Behroozizad, R.M. Nambiar and Z. Amir, "Sociocultural theory as an approach to aid EFL learners," Reading, vol. 14, pp. 217-226, 2014.

[7] J.C. McCroskey and V.P. Richmond, "Willingness to communicate: A cognitive view," Journal of Social Behavior and Personality, vol. 5, pp. 19-37, 1990.

[8] J.E. Peng and L. Woodrow, "Willingness to communicate in English: A model in the Chinese EFL classroom context," Language learning, vol. 60, pp. 834-876, 2010.

[9] Y. Liu and H. Park, "A study of Korean EFL learners' WTC and motivation," Journal of Pan-Pacific Association of Applied Linguistics, vol. 16, pp. 35-58, 2012

[10] C.R. Kost, "Use of communication strategies in a synchronous CMC environment," in Mediating Discourse Online, S.S. Magnan, Ed. Amsterdam, the Netherlands: John Benjamins, 2008, pp. 153-189.

[11] R. Kern and M. Warschauer, "Introduction: Theory and practice of networked-based language teaching," in Network-based Language Teaching: Concepts and Practice, M. Warschauer and R. Kern, Eds. New York, NY: Cambridge University Press, 2000, pp. 1-19.

[12] L. Ortega, "Interaction and attention to form in L2 text-based computermediated communication," in Multiple Perspectives on Interaction, A. 
Mackey and C. Polio, Eds. New York, NY: Routledge, 2009, pp. 226253.

[13] B. Smith, "Computer-mediated negotiated interaction and lexical acquisition," Studies in Second Language Acquisition, vol. 26, pp. 365398, 2004.

[14] S. Sauro and B. Smith, "Investigating L2 performance in text chat," Applied Linguistics, vol. 31, pp. 554-577, 2010.

[15] I. Yanguas, "Oral computer-mediated interaction between L2 learners: It's about time," Language Learning \& Technology, vol. 14, pp. 72-93, 2010 .

[16] M. Warschauer, "Comparing face-to-face and electronic discussion in the second language classroom," CALICO Journal, vol. 13, pp. 7-25, 1996.

[17] J.M. Hudson and A.S. Bruckman, "IRC Francais: The creation of an Internet-based SLA community," Computer Assisted Language Learning, vol. 15, pp. 109-134, 2002.

[18] R. Godwin-Jones, "Emerging technologies---Web-writing 2.0: Enabling, documenting and assessing writing online," Language Learning \& Technology, vol. 12, pp. 7-13, 2008.
[19] M.P. Stevenson and M. Liu, "Learning a Language with Web 2.0: Exploring the use of social networking features of foreign language learning websites," CALI CO Journal, vol. 27, pp. 1-8, 2010.

[20] K. Lee and L. Ranta, "Facebook: Facilitating social access and language acquisition for international students?" TESL Canada Journal, vol. 31, pp. 22-50, 2014.

[21] H.-T. Hung and S.C.-Y. Yuen, "Educational use of social networking technology in higher education," Teaching in Higher Education, vol. 15, pp. 703-714, 2010.

[22] N.B. Ellison, C. Steinfield and C. Lampe, "The benefits of Facebook 'friends': Social capital and college students' use of online social network sites," Journal of Computer-Mediated Communication, vol. 12, pp. 1143-1168, 2007.

[23] M.K. Kabilan, N. Ahmad and M.J.Z. Abidin, "Facebook: An online environment for learning of English in institutions of higher education?" Internet and Higher Education, vol. 13, pp. 179-187, 2010.

[24] K. Newgarden, “Twitter,” TESL-EJ, vol. 13, pp. 1-13, 2009. 